\title{
Assessment of the Patient Movement for Lesion during Myocardial Perfusion SPECT Imaging by Cardiac Phantom
}

\author{
Eser Erim¹, Turkan Ertay2, Ismail Evren², Mine Eren², Cengiz Tasci³, Hatice Durak² \\ ${ }^{1}$ Department of Medical Physics, Institute of Health Sciences, Dokuz Eylul University, İzmir, Turkey \\ ${ }^{2}$ Department of Nuclear Medicine, School of Medicine, Dokuz Eylul University, İzmir, Turkey \\ ${ }^{3}$ Gama Nuclear Medicine Center, Gaziantep, Turkey \\ Email: turkan.ertay@deu.edu.tr
}

Received 25 February 2015; accepted 24 April 2015; published 30 April 2015

Copyright (C) 2015 by authors and Scientific Research Publishing Inc.

This work is licensed under the Creative Commons Attribution International License (CC BY). http://creativecommons.org/licenses/by/4.0/

(c) (i) Open Access

\begin{abstract}
Movement of the patient during myocardial perfusion SPECT leads to some artifacts that make the interpretation difficult. In this study, myocardial perfusion imaging protocol was performed on a cardiac phantom and SPECT was performed by simulating patient movements. A lesion model with dimensions of $1.2 \times 2 \times 2 \mathrm{~cm}$ was created on the inferoseptal wall of the cardiac phantom. Imaging was done in circular orbits in $64 \times 64$ matrix and step and shoot mode. First set of images taken with no movement was referred as the reference image. During imaging, patient movement was simulated by moving the phantom in $\pm X$ and $\pm Y$ directions between the frames starting from $8^{\text {th }}$ frame to $16^{\text {th }}$ frame. At the end of imaging, Bull's eye maps of images with movement were compared with Bull's eye maps of reference images. Bull's eye maps were evaluated by an experienced nuclear medicine physician. Shifting patient's movement in all directions by \pm 1 and $\pm 2 \mathrm{~cm}$, displaced the localization of the lesion mildly and this did not hamper the evaluation. However, movements of \pm 3 or $\pm 4 \mathrm{~cm}$ resulted in artifacts which in turn caused partial or no visualization of the lesion. In motion corrected images, the lesion could be evaluated in \pm 1 and $\pm 2 \mathrm{~cm}$ movements while lesion could not be evaluated in \pm 3 and $\pm 4 \mathrm{~cm}$ movements. As a result, movement greater than $\pm 3 \mathrm{~cm}$ causes significant image artifacts and this should be considered as a potential source of error in myocardial perfusion studies.
\end{abstract}

\section{Keywords}

SPECT, Myocardial Perfusion Scintigraphy, Cardiac Phantom

How to cite this paper: Erim, E., Ertay, T., Evren, I., Eren, M., Tasci, C. and Durak, H. (2015) Assessment of the Patient Movement for Lesion during Myocardial Perfusion SPECT Imaging by Cardiac Phantom. World Journal of Nuclear Science and Technology, 5, 129-139. http://dx.doi.org/10.4236/wjnst.2015.52013 


\section{Introduction}

SPECT systems are based on rotation of one or more cameras around the patients. Information is gathered in certain angles of rotation of the detector around the patient, then section images are obtained on the computer by using iterative or back projection filtration techniques [1]-[5]. Images in projection series in SPECT systems are re-structured by an algorithm called back projection. Projection data can be produced in transverse sections also named as axial or transaxial and images in sagittal or coronal sections can be obtained by mathematical procedures as well [6]-[8]. Due to long acquisition times in myocardial perfusion SPECT, patients tend to move in different directions by changing position in order to feel comfortable [9]. However, patient movement during myocardial perfusion SPECT imaging results in image artifacts [1] [2].

General patient movements during SPECT include constant body motion, periodic local deformations and non-local deformations. Breathing and heart beat are periodic local deformations. When the term "constant body motion" is used, the patient should be considered as a fixed substance. Possible motions include turning and rotating in three dimensions [10].

Of all patient movements that cause deformation, it is easier to correct the effects of constant body motions because data are processed by comparing the images obtained without effect of motion during imaging.

Some techniques are developed for the quantitative analysis of planar or SPECT myocardial perfusion images. Quantitative programs may be more efficient compared to visual evaluations. Stress perfusion quantization is compared with resting perfusion in order to evaluate spread and intensity of the ischemia. One approach is to generate a polar map by taking sections from apex of the heart toward base in short axis SPECT. This quantitative analysis is generally visualized as Bull's eye or polar map Due to normalizing regional scores to largest voxel value on myocardial wall and largest voxel value adjusted to 100 at Quantitative Perfusion SPECT (QPS), most of the uniform images have an average regional score and a small standard deviation [11]-[13].

Some techniques have been developed for the detection and correction of translational patient motion in dynamic and static myocardial SPECT studies [14]-[18].

The effect of patient movement on lesion detection was examined in this study. In addition, by using the motion correction option in image processing, ability of compensation of movement effect in various directions and magnitudes was assessed. Myocardial perfusion imaging protocol was performed on a cardiac phantom with lesion and SPECT was performed by simulating patient movements.

\section{Materials and Methods}

\subsection{Cardiac Insert Phantom}

Cardiac insert phantom used in this study had a $8 \mathrm{~cm}$ diameter and height and a $0.5 \mathrm{~cm}$ wall thickness. Bolus (A tissue-equivalent substance) with dimensions of $1.2 \times 2.0 \times 2.0 \mathrm{~cm}$ that mimics a perfusion defect in the phantom image was used. Cardiac insert phantom was placed in the same coordinate axis in all imaging procedures. Preparation of cardiac insert phantom took place in laboratory to prevent risk of contamination. The phantom was filled with water, and water was mixed until no bubbles existed. In nuclear medicine, clinical practice, 15 - $30 \mathrm{mCi}$ 99mTc MIBI is injected to the patient for myocardial perfusion scintigraphy and the myocardial uptake of 99mTc-sestamibi is $1.2 \%-1.5 \%$ of the injected dose [19]. Thus $1 \mathrm{mCi} 99 \mathrm{mTc}$ was placed in the phantom corresponding to the extracted amount $99 \mathrm{mTc}$ with $1 \mathrm{mCi}$ activity. Experimental setup is shown in Figure 1.

Assuming that patient movement occurs just in the middle of the imaging, the phantom was moved starting from the middle of imaging that is right after the 8th frame with a total of 16 frames, i.e. During imaging, the phantom was moved from the origin of $\pm X$ and $\pm Y$ axes in one cm steps up to $4 \mathrm{~cm}$ starting between frame 8 and 16 and the effect of this motion at each $\mathrm{cm}$ was evaluated quantitatively and visually in comparison to reference the image.

\subsection{Imaging Protocol}

Double detector-Philips Forte JETstream AZ SPECT is used with a VXGP collimator. 64 Images were obtained in on $64 \times 64$ matrix with no zooming. Minimum of 100,000 counts were collected during each acquisition. Imaging was performed by double detectors starting on 45 degrees right anterior oblique and ending at 135 degrees left posterior oblique in a total of 180 degrees in a circular orbit by step and shoot mode. Energy window was set at 20\% for $99 \mathrm{mTc}$ at $140 \mathrm{keV}$. Butterworth filter was used for processing. 


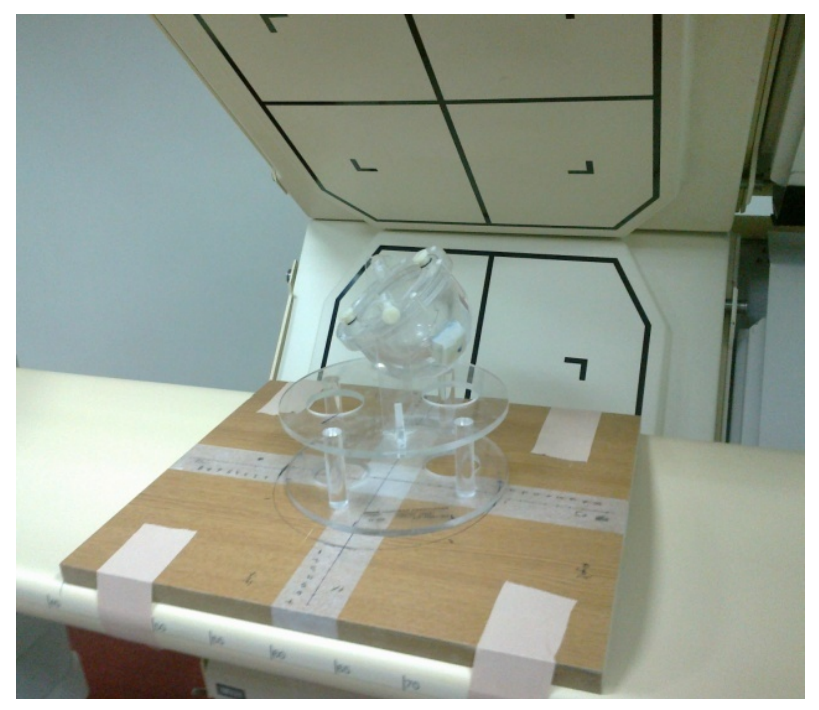

Figure 1. Experimental setup.

\subsection{Evaluation of Images}

Images were reconstructed with Philips JETstream Workspace V3.5 version. For interpretation each image, with a motion effect is recorded in data registration form after comparison with reference image according to grading table (Table 1). Site of lesion was determined on image with no motion effect, which we considered as the reference. We created a reference image with 20 segments in the Bull's eye map (Figure 2). Blinded image evaluation was performed by independent two Nuclear Medicine Specialist. Area with maximum activity was considered as 100 and mapping was done using the ratio of the lesion-site to maximum. The study was performed using gamma camera Philips Forte Jet stream AZ SPECT which is applied Cedars-Sinai Motion Correction (MoCo) algorithm.

Mild is described as, low activity up to 3 regions.

Severe is described as, low activity in more than 3 regions.

In order to describe the location of the lesion and its neighborhood in Bull's eye image, schematic visualization was shown (Figure 3).

\section{Results}

Lesion is localized at 7 o'clock position. The reference image is shown in Figure 2.

In early frame for example frame 9 no lesion was visible at the true lesion site but additional lesion was seen Bull's eye map without motion correction (Figure 4). True lesion exists with additional lesions with motion correction effect (Figure 5). Graphic 1 shows uptake in the lesion according to the reference without motion correction for frame 9, Graphic 2 shows uptake in the lesion according to the reference with motion correction for frame 9 ,

For late frame for example frame 15 no lesion was visible at the true lesion site but additional lesion was seen Bull's eye map without motion correction (Figure 6). True lesion partially exists with additional lesions with motion correction (Figure 7). Graphic 3 shows uptake in the lesion according to the reference without motion correction for frame 15, Graphic 4 shows uptake in the lesion according to the reference with motion correction for frame 15.

Tables show grading with motion correction (Table 2) and without motion correction (Table 3).

In movement in $-\mathrm{X} 1$ and $+\mathrm{X} 1$, the lesion was on the real localization site but additional lesions was seen in early and late frames.

In movement $-\mathrm{X} 2$, the lesion was partially on the real localization site but additional lesions were seen in neighbor regions.

In movement $+\mathrm{X} 2$, the lesion was not seen on the real localization site but additional lesions were seen in neighbor regions. 


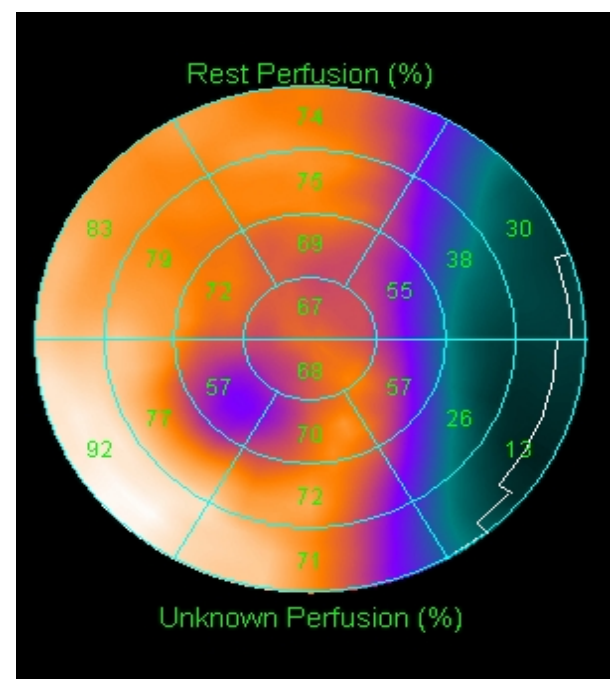

Figure 2. Bull's eye map of the reference image (no motion effect).

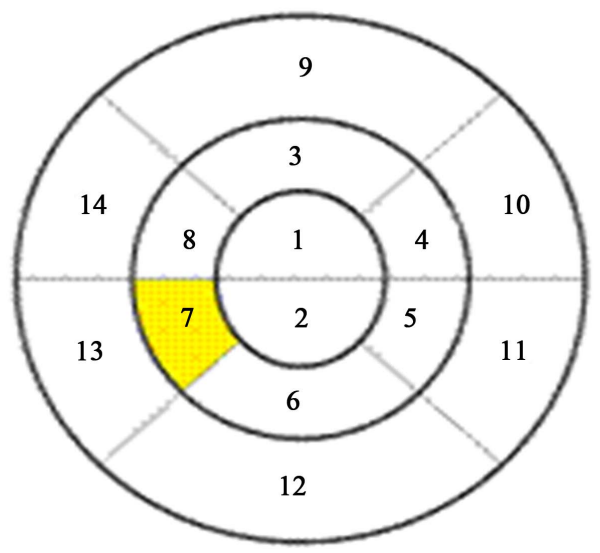

Figure 3. Schematic visualization of Bull's eye map.

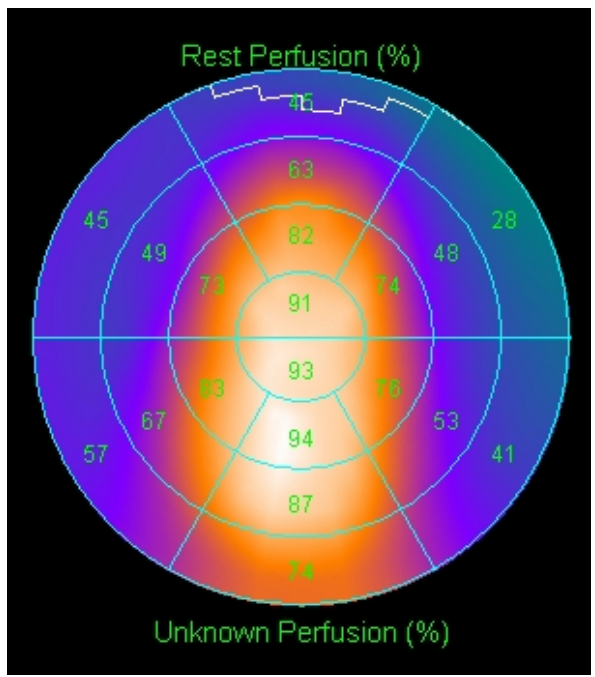

Figure 4. Bull's eye map (frame $9,+\mathrm{X} 4 \mathrm{~cm}$ ) (without motion correction) $2 \mathrm{C}$. 


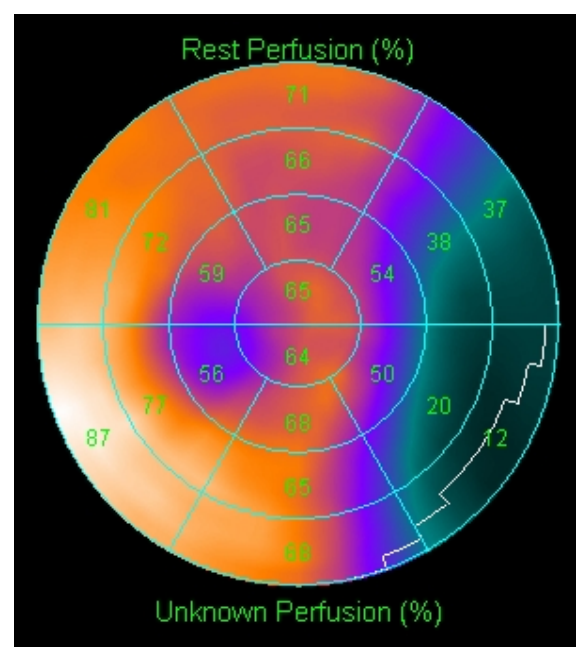

Figure 5. Bull's eye map (frame 9, $+\mathrm{X} 4 \mathrm{~cm}$ ) (with motion correction) $1 \mathrm{C}$.

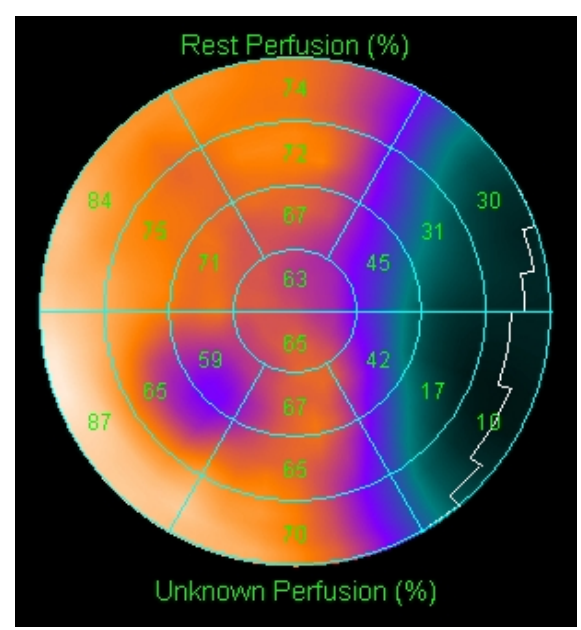

Figure 6. Bull's eye map (frame 15, $+\mathrm{X} 4 \mathrm{~cm}$ ) (without motion correction) $2 \mathrm{~B}$.

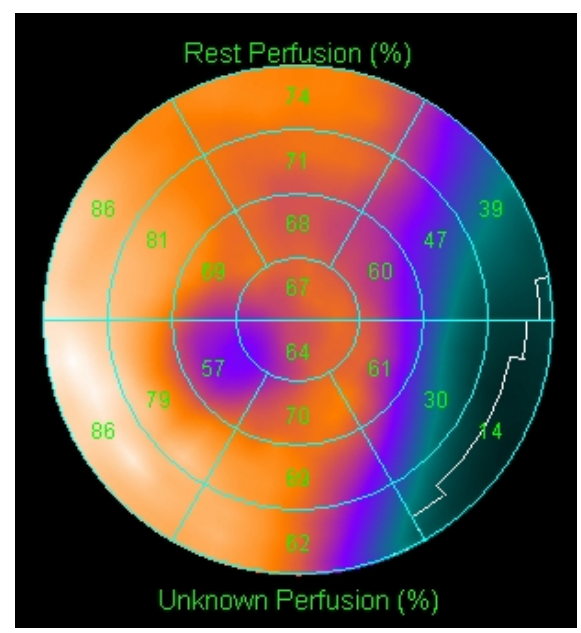

Figure 7. Bull's eye map (frame 15, $+\mathrm{X} 4 \mathrm{~cm}$ ) (with motion correction) $3 \mathrm{~B}$. 
Frame 9

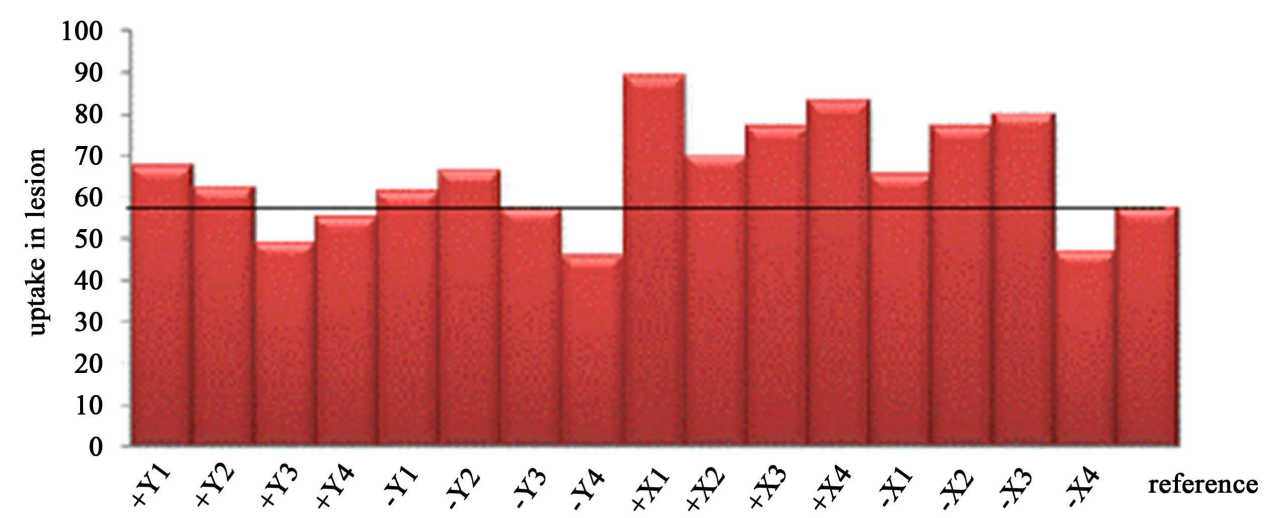

moving direction

Graphic 1. For frame 9, uptake in the lesion according to the reference without motion correction.

Frame 9

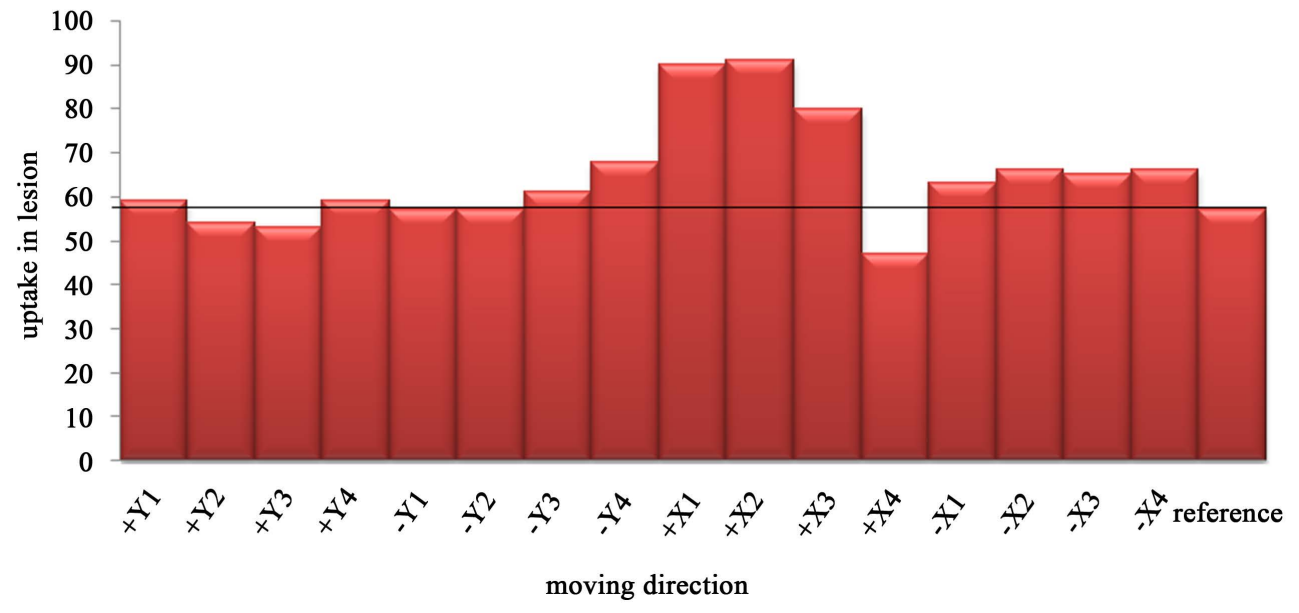

Graphic 2. For frame 9, uptake in the lesion according to the reference with motion correction.

Frame 15

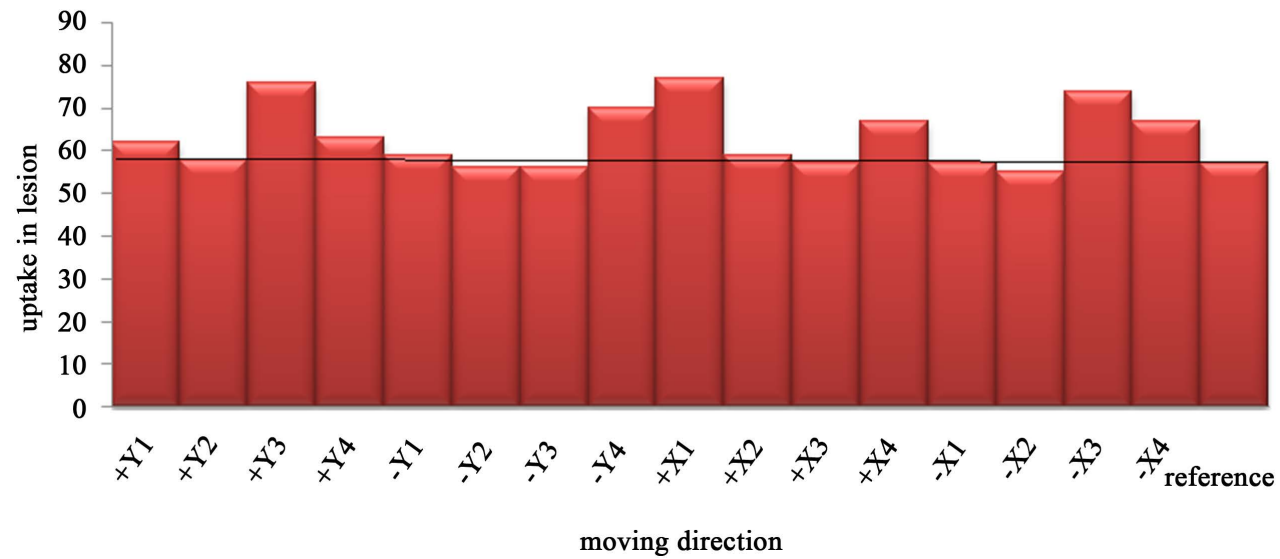

Graphic 3. For frame 15, uptake in the lesion according to the reference without motion correction. 


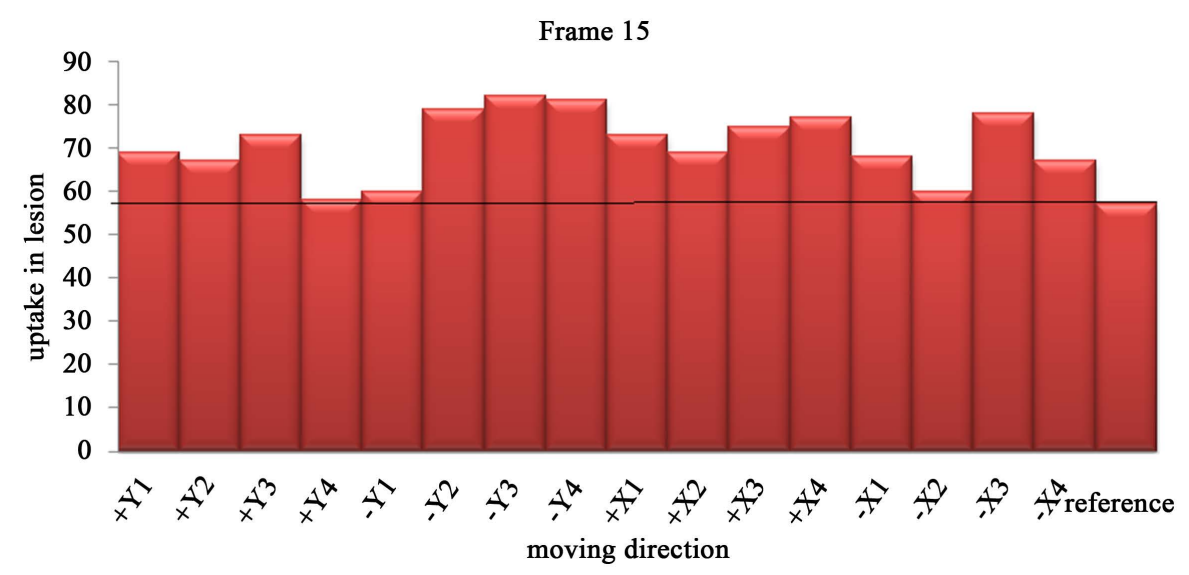

Graphic 4. For frame 15, uptake in the lesion according to the reference with motion correction.

Table 1. Grading of the lesion presence and site.

\begin{tabular}{|cc|}
\hline 1. True lesion exists with & \\
\hline No additional lesion & $1 \mathrm{~A}$ \\
Mild additional lesion & $1 \mathrm{~B}$ \\
Severe additional lesion & $1 \mathrm{C}$ \\
\hline 2. No lesion is visible at the true lesion site with & $2 \mathrm{~A}$ \\
\hline No additional lesion & 2B \\
Mild additional lesion & 2C \\
\hline Severe additional lesion & \\
\hline 3. True lesion partially exists with & $3 \mathrm{~A}$ \\
\hline No additional lesion & $3 \mathrm{~B}$ \\
Mild additional lesion & $3 \mathrm{C}$ \\
\hline
\end{tabular}

Table 2. Grading with motion correction.

\begin{tabular}{|c|c|c|c|c|c|c|c|c|c|}
\hline & FRAME 8 & FRAME 9 & FRAME 10 & FRAME 11 & FRAME 12 & FRAME 13 & FRAME 14 & FRAME 15 & FRAME16 \\
\hline$+\mathrm{Y} 1$ & 1B & $3 B$ & $1 \mathrm{~B}$ & $1 \mathrm{~B}$ & $2 \mathrm{~B}$ & $1 \mathrm{~B}$ & $2 B$ & 3B & $3 B$ \\
\hline$+\mathbf{Y} 2$ & $2 \mathrm{C}$ & 1B & $1 \mathrm{~B}$ & $1 \mathrm{~B}$ & $1 \mathrm{~B}$ & $2 \mathrm{~A}$ & $1 \mathrm{~B}$ & 3B & 3B \\
\hline$+\mathbf{Y 3}$ & $2 \mathrm{~B}$ & $1 \mathrm{~B}$ & $3 C$ & $2 \mathrm{~B}$ & $2 \mathrm{~B}$ & 3B & $2 \mathrm{~A}$ & $2 \mathrm{~B}$ & $2 \mathrm{~B}$ \\
\hline$+\mathrm{Y} 4$ & $2 B$ & $3 C$ & $1 \mathrm{~A}$ & $1 \mathrm{~B}$ & $2 B$ & $1 \mathrm{~B}$ & $3 B$ & 3B & $1 \mathrm{~B}$ \\
\hline$-\mathrm{Y1}$ & $1 \mathrm{~B}$ & $1 \mathrm{~B}$ & 1B & $1 \mathrm{~B}$ & $1 \mathrm{~B}$ & $1 \mathrm{~B}$ & $2 \mathrm{~B}$ & $1 \mathrm{~B}$ & $3 \mathrm{C}$ \\
\hline$-\mathrm{Y} 2$ & $1 \mathrm{~B}$ & $1 \mathrm{~A}$ & 3В & $1 \mathrm{~B}$ & 3В & $1 \mathrm{~B}$ & $1 \mathrm{~B}$ & $1 \mathrm{~B}$ & $1 \mathrm{~B}$ \\
\hline$-\mathbf{Y 3}$ & $1 \mathrm{~B}$ & $1 \mathrm{~A}$ & $1 \mathrm{~A}$ & $2 B$ & 3B & $1 \mathrm{~B}$ & $3 C$ & $1 \mathrm{~A}$ & $1 \mathrm{~B}$ \\
\hline$-Y 4$ & $2 B$ & 3B & $1 \mathrm{C}$ & $1 \mathrm{~B}$ & $1 \mathrm{~B}$ & $1 \mathrm{~B}$ & 3B & $2 B$ & 3B \\
\hline$+\mathrm{X} 1$ & $2 B$ & $2 B$ & $2 B$ & $2 \mathrm{~B}$ & $2 B$ & $1 \mathrm{~B}$ & $2 \mathrm{~A}$ & $2 \mathrm{~A}$ & $1 \mathrm{~B}$ \\
\hline$+\mathrm{X} 2$ & $2 B$ & $2 \mathrm{C}$ & $2 \mathrm{~B}$ & $2 \mathrm{~B}$ & $2 \mathrm{~B}$ & $2 B$ & 3B & $1 \mathrm{~B}$ & 3B \\
\hline$+\mathrm{X} 3$ & $2 \mathrm{C}$ & $2 \mathrm{C}$ & $2 \mathrm{C}$ & $1 \mathrm{C}$ & $2 B$ & 3B & $2 \mathrm{~B}$ & $1 \mathrm{~B}$ & 3B \\
\hline$+\mathrm{X} 4$ & $3 C$ & $1 \mathrm{C}$ & $1 \mathrm{C}$ & 3B & 3C & $2 B$ & $1 \mathrm{~B}$ & 3B & $1 \mathrm{~B}$ \\
\hline$-\mathrm{X} 1$ & 3B & $2 \mathrm{~B}$ & $2 \mathrm{~B}$ & $3 B$ & 3B & 1B & $2 \mathrm{~B}$ & $1 \mathrm{~B}$ & $2 \mathrm{~B}$ \\
\hline$-\mathrm{X} 2$ & 3B & $2 \mathrm{~B}$ & 3B & 3B & 3B & 3B & 1B & 1B & 2B \\
\hline$-\mathrm{X} 3$ & 3B & $2 \mathrm{~B}$ & 3B & 3B & 3B & $2 B$ & $1 \mathrm{~B}$ & $2 \mathrm{~B}$ & $1 \mathrm{~A}$ \\
\hline$-\mathrm{X} 4$ & $2 \mathrm{~B}$ & $2 \mathrm{C}$ & 3B & $1 \mathrm{C}$ & $3 C$ & 3B & $3 \mathrm{~A}$ & $2 \mathrm{~B}$ & $2 \mathrm{~B}$ \\
\hline
\end{tabular}


Table 3. Grading without motion correction.

\begin{tabular}{|c|c|c|c|c|c|c|c|c|c|}
\hline & FRAME 8 & FRAME 9 & FRAME 10 & FRAME 11 & FRAME 12 & FRAME 13 & FRAME 14 & FRAME 15 & FRAME16 \\
\hline$+\mathrm{Y1}$ & 3B & 3B & $3 B$ & 3B & $2 \mathrm{~B}$ & $2 B$ & 3B & $3 C$ & $2 B$ \\
\hline$+\mathbf{Y} 2$ & $2 \mathrm{~B}$ & $2 B$ & 3B & $2 B$ & 3B & $2 \mathrm{C}$ & 3B & $3 C$ & 3B \\
\hline$+\mathbf{Y} 3$ & $3 C$ & $1 \mathrm{C}$ & $3 C$ & $2 B$ & $2 B$ & $2 \mathrm{C}$ & $2 B$ & $2 \mathrm{C}$ & $2 \mathrm{C}$ \\
\hline$+Y 4$ & $2 \mathrm{C}$ & $1 \mathrm{C}$ & $3 C$ & $2 B$ & 3B & $2 \mathrm{C}$ & $2 \mathrm{C}$ & $1 \mathrm{~B}$ & 3B \\
\hline$-\mathbf{Y 1}$ & 3B & $1 \mathrm{~B}$ & 3B & $1 \mathrm{~B}$ & 3B & $1 \mathrm{~B}$ & $2 \mathrm{~B}$ & 3B & 3B \\
\hline$-\mathbf{Y} 2$ & 3B & $1 \mathrm{~B}$ & $2 B$ & $2 B$ & $2 \mathrm{~B}$ & $2 B$ & $2 B$ & $3 B$ & 1B \\
\hline$-\mathbf{Y 3}$ & $3 C$ & $3 \mathrm{C}$ & $1 \mathrm{C}$ & $2 \mathrm{C}$ & $3 C$ & $2 \mathrm{C}$ & $2 \mathrm{~B}$ & $3 C$ & $2 \mathrm{~B}$ \\
\hline$-Y 4$ & $3 C$ & $1 \mathrm{C}$ & $1 \mathrm{C}$ & $3 \mathrm{C}$ & $3 C$ & $2 B$ & $2 B$ & $1 \mathrm{~B}$ & $3 \mathrm{C}$ \\
\hline$+\mathrm{X} 1$ & $2 B$ & $2 \mathrm{~B}$ & $2 B$ & $2 \mathrm{~B}$ & $2 \mathrm{~B}$ & $3 B$ & $2 \mathrm{~B}$ & $2 B$ & 1B \\
\hline$+\mathrm{X} 2$ & $2 \mathrm{C}$ & $3 C$ & $2 \mathrm{C}$ & $2 \mathrm{~B}$ & 3B & $2 B$ & $2 \mathrm{~B}$ & $2 B$ & $1 \mathrm{~B}$ \\
\hline$+\mathrm{X} 3$ & $3 C$ & $2 \mathrm{C}$ & $1 \mathrm{C}$ & $3 \mathrm{C}$ & $1 \mathrm{C}$ & 3В & $2 \mathrm{~B}$ & $2 B$ & $3 B$ \\
\hline$+\mathrm{X} 4$ & $3 C$ & $2 \mathrm{C}$ & 1B & 3B & 3B & 3B & $2 \mathrm{~B}$ & $2 \mathrm{~B}$ & 3B \\
\hline$-\mathrm{X} 1$ & 3B & 3B & 3B & 3B & 3B & $1 \mathrm{~B}$ & 3B & $2 B$ & $2 B$ \\
\hline$-\mathrm{X} 2$ & $2 \mathrm{~B}$ & $2 \mathrm{~B}$ & $2 \mathrm{~B}$ & $2 \mathrm{~B}$ & $2 \mathrm{~B}$ & 3B & 3B & $1 \mathrm{~B}$ & 3B \\
\hline$-\mathbf{X} 3$ & $2 B$ & $2 \mathrm{~B}$ & $1 \mathrm{C}$ & $1 \mathrm{C}$ & $1 \mathrm{C}$ & 3B & 3B & $2 B$ & 1B \\
\hline$-X 4$ & $2 B$ & $1 \mathrm{C}$ & $1 \mathrm{C}$ & $1 \mathrm{C}$ & $1 \mathrm{C}$ & $3 B$ & $3 C$ & $3 B$ & $3 B$ \\
\hline
\end{tabular}

In movement $-\mathrm{X} 3$ the lesion was seen partially on the real localization site but additional lesions were seen in neighbor regions in the early frames. In the late frames, lesion was seen on the real localization site but additional lesions were seen in neighbor regions.

In movement $+\mathrm{X} 3$, the lesion was not seen on the real localization site but additional lesions were seen in neighbors regions in early frame, in the late frames, lesion was seen on the real site but additional lesions were seen in neighbor regions.

In movement $-\mathrm{X} 4$ and $+\mathrm{X} 4$, the lesion was partially on the real localization site or not but additional lesions were seen in neighbor regions.

In movement $-\mathrm{Y} 1$ and $+\mathrm{Y} 1$, the lesion was partially on the real localization site but additional lesions were seen in neighbor regions.

In movement $-\mathrm{Y} 2$, the lesion was on the real localization site but additional lesions were seen in neighbor regions.

In movement $+Y 2$, the lesion was not on the real localization site in early frames, but additional lesions were seen in neighbor regions in late frames.

In movement -Y3 the lesion was partially on the real localization site but additional lesions were seen in neighbors regions.

In movement $+Y 3$, the lesion was not on the real localization site but additional lesions were seen in early frames but the lesion was on the real localization site with additional lesions in late frames.

In movement + Y4 the lesion was not seen on the real localization site but additional lesions were seen in neighbors regions in the early frames. The lesion was seen on the real localization site and additional lesions were seen in the neighbor regions in the late frames.

In movement -Y4 the lesion was seen on the real localization site but additional lesions were seen in neighbors regions in the early and late frames.

\section{Discussion}

It is reported that about $25 \%$ of the patients move during myocardial perfusion SPECT imaging. As imaging 
takes place, patient's movement can produce false perfusion defects or hide the present perfusion defects. With a long duration of imaging, the patient tends to move on the imaging bed [18]. Detection and correction of patient movement are of utmost importance in SPECT imaging and motion correction should be performed to obtain correct slices. Various programs and techniques were developed in order to correct these defects [15]-[17].

Possible patient movements during SPECT imaging include constant body motion, periodic local deformations and non-local deformations. Constant body motion is movement in three dimensions. Artifacts caused by movements due to cardiac contractions and breathing can be classified as periodic local deformations. Non-local deformations are the patient's curling, and bending movements during the process [10].

In a study on artifacts caused by breathing, Kovalski et al. found that rate of artifacts for each of 20 patients was $3.75 \%$ on average before correction. They observed that after motion correction this rate decreased to $1.58 \%$ [13] [20] [21].

Philippe et al. set up a visual follow up system in order to perceive patient's movement. Patient's movement during SPECT was detected with an external equipment (visual tracking system, VTS), secondly, condition related to patient motion was identified by processing the data and thirdly, a synchronization was created between optic camera imaging and SPECT by correcting movement in artifacts [16].

Germano et al. reported that there was no need to correct movements less than $6.5 \mathrm{~mm}$ and false-positive findings between $5 \%$ and $40 \%$ was also reported for a $6.5 \mathrm{~mm}$ simulated axial motion in the middle of ${ }^{201} \mathrm{Tl}$ SPECT studies [18]. Glenn et al. reported that artifact occurring due to a movement of 6 - 8 mm produced moderate and correctable errors while artifacts caused by movements bigger than $8 \mathrm{~mm}$ resulted in severe errors that might affect clinical interpretation [22].

Cooper et al. found that vertical motion produced more artifacts than lateral motion. They reported that patient movement of $6.5 \mathrm{~mm}$ can be detected, but clinically significant artifacts occur in movements equal to or bigger than $13 \mathrm{~mm}$ [23]. In a study done with single and double-headed gamma cameras, Matsumo et al. investigated the effects of motion in different cameras. They found that average defect rates in the left ventricle with $6.4 \mathrm{~mm}$ of movement in single and double headed gamma cameras were $0.6 \%$ and $0.8 \%$, respectively. They also reported that average defect rates in the left ventricle with $12.8 \mathrm{~mm}$ of movement in single and double headed gamma cameras were $3.8 \%$ and $5.7 \%$, respectively. Average defect rates in the left ventricle with $19.2 \mathrm{~mm}$ of movement in single and double headed gamma cameras were $8.1 \%$ and $11.8 \%$, respectively [10]. These findings suggest that there is a correlation between amount of patient motion and that of perfusion defect. The reason for the percentage of artifacts originating from double headed cameras are theoretically higher is that several projections are obtained simultaneously. On the other hand, since single detector cameras need to collect the same number of counts, acquisition time for these cameras is longer and this condition diminishes sensitivity while producing artifacts due to patient motion [10] [24]-[26]. William et al. reported that artifacts resulting from motion can be eliminated successfully in a cardiac imaging study done with ${ }^{201} \mathrm{Tl}$ using phantom and they also noted that image quality improved by more than $50 \%$ in a study involving 36 different patients [27].

In our study, when motion correction was applied, movements of \pm 1 and $\pm 2 \mathrm{~cm}$ were compared with images corresponding reference image. Image artifacts produced by movement in vertical and lateral axis were different in severity. As stated in the literature, severity of artifact in vertical axis was more prominent.

Distortion or early distortion was observed in all frames at $\pm 3 \mathrm{~cm}$ motions, albeit different in severity. The images that we considered as unusable were processed by motion correction, images near equivalent to reference image were obtained. Motion of $\pm 4 \mathrm{~cm}$ resulted in distorted images in all axis. Location and severity of the lesion could not be defined and severe distortions were seen. It was concluded that at $4 \mathrm{~cm}$ all images were distorted with no relation to axis direction even if motion correction was used. In some images, motion correction could not be applied because of excessive movement.

As a result, we observed that patient's motion of $\pm 1 \mathrm{~cm}$ and $\pm 2 \mathrm{~cm}$ that occurs towards last frames of the imaging produces tolerable artifacts in the assessment of the image, movement greater than $\pm 3 \mathrm{~cm}$ causes significant image artifacts and this should be considered as a potential source of error in myocardial perfusion studies. In motion corrected images, the lesion could be evaluated in \pm 1 and $\pm 2 \mathrm{~cm}$ movements while lesion could not be evaluated in \pm 3 and \pm 4 cm movements.

\section{Conclusions}

Patient motion during myocardial perfusion SPECT imaging studies can produce an image with artifacts mi- 
micking perfusion defects leads to false-positive findings.

The impact of various types and degrees of patient motion evaluated for the lesion is even more crucial. Patient's motion occurs at last frames of the imaging process that can be tolerable artifacts in the image.

All of the images reconstructed by motion correction technique had better quality. Shifting patient's movement in all directions by \pm 1 and $\pm 2 \mathrm{~cm}$, displaced the localization of the lesion mildly and this did not hamper the evaluation. However, movements of \pm 3 or $\pm 4 \mathrm{~cm}$ resulted in artifacts which in turn caused partial or no visualization of the lesion.

\section{References}

[1] Wheat, J.M. and Currie, G.M. (2004) Incidence and Characterization of Patient Motion in Myocardial Perfusion SPECT: Part 1. Journal of Nuclear Medicine Technology, 32, 60-65.

[2] Nadine, S. and Andrew, W. (2011) Introduction to Medical Imaging. Physics, Engineering and Clinical Applications, 94-114.

[3] Tsui, B.M.W. (1992) Reconstruction and Filtering Methods for Quantitative Cardiac SPECT Imaging Cardiovascular Nuclear Medicine and MRI. Developments in Cardiovascular Medicine, 128, 29-45. http://dx.doi.org/10.1007/978-94-011-2666-3 2

[4] Elschot, M., Nijsen, J.F.W., Dam, A.J. and de Jong, H.W.A.M. (2011) Quantitative Evaluation of Scintillation Camera Imaging Characteristics of Isotopes Used in Liver Radioembolization. http://dx.doi.org/10.1371/journal.pone.0026174

[5] Thomas, A., Brian, G., Mouaz, A. and Dennis, A. (2010) Single Photon-Emission Computed Tomography. Journal of the American College of Cardiology, 2-10.

[6] Lin, G.S., Hines, H.H., Grant, G., Taylor, K. and Ryals, C. (2006) Automated Quantification of Myocardial Ischemia and Wall Motion Defects by Use of Cardiac SPECT Polar Mapping and 4-Dimensional Surface Rendering. Journal of Nuclear Medicine Technology, 34, 13-17.

[7] Zakavi, S.R., Zonoozi, A., Kakhki, V.D., Hajizadeh, M., Momennezhad, M. and Ariana, K. (2006) Image Reconstruction Using Filtered Backprojection and Iterative Method: Effect on Motion Artifacts in Myocardial Perfusion SPECT. Journal of Nuclear Medicine Technology, 34, 220-223.

[8] Fokas, A.S., Iserles, A. and Marinakis, V. (2006) Reconstruction Algorithm for Single Photon Emission Computed Tomography and Its Numerical Implementation. Journal of the Royal Society Interface, 22, 45-54. http://dx.doi.org/10.1098/rsif.2005.0061

[9] Anagnostopoulos, C., Neill, J., Reyes, E. and Prvulovich, E. (2012) Myocardial Perfusion Scintigraphy: Technical Innovations and Evolving Clinical Applications. Heart, 98, 353-359. http://dx.doi.org/10.1136/heartjnl-2011-300678

[10] Matsumoto, N., Berman, D.S., Kavanagh, P.B., Gerlach, J., Hayes, S.W., Lewin, H.C., Friedman, J.D. and Germano, G. (2001) Quantitative Assessment of Motion Artifacts and Validation of a New Motion-Correction Program for Myocardial Perfusion SPECT. Journal of Nuclear Medicine, 42, 687-694.

[11] Holly, T.A., Abbott, B.G., Al-Mallah, M., Calnon, D.A., Cohen, M.C., DiFilippo, F.P., et al. (2010) Single PhotonEmission Computed Tomography. Journal of Nuclear Cardiology, 17, 941-973. http://dx.doi.org/10.1007/s12350-010-9246-y

[12] Bai, C.Y., Conwell, R., Kindem, J., Babla, H., Gurley, M., De Los Santos II, R., et al. (2010) Phantom Evaluation of a Cardiac SPECT/VCT System that Uses a Common Set of Solid-State Detectors for both Emission and Transmission Scans. Journal of Nuclear Cardiology, 17, 459-469. http://dx.doi.org/10.1007/s12350-010-9204-8

[13] Kovalski, G., Israel, O., Keidar, Z., Frenkel, A., Sachs, J. and Azhari, H. (2007) Correction of Heart Motion Due to Respiration in Clinical Myocardial Perfüsion SPECT Scans Using Respiratory Gating. Journal of Nuclear Medicine, 48, 630-636. http://dx.doi.org/10.2967/jnumed.106.037390

[14] Wheat, J.M. and Currie, G.M. (2004) Incidence and Characterization of Patient Motion in Myocardial Perfusion SPECT: Part 1. Journal of Nuclear Medicine Technology, 32, 60-65.

[15] Schumacher, H. and Fisher, B. (2007) A New Approach Motion Correction in SPECT Imaging. In: Bildverarbeitung für die Medizin, 51-55.

[16] Bruyant, P.P., Gennert, M.A., Speckert, G.C., Beach, R.D., Morgenstern, J.D., Kumar, N., Nadella, S. and King, M.A. (2005) A Robust Visual Tracking System for Patient Motion Detection in SPECT: Hardware Solutions. IEEE Transactions on Nuclear Science, 52, 1288-1294. http://dx.doi.org/10.1109/TNS.2005.858208

[17] Gennert, M.A., Bruyant, P.P., Narayanan, M.V. and King, M.A. (2003) Assessing a System to Detect Patient Motion in SPECT Imaging Using Stereo Optical Cameras. IEEE Nuclear Science Symposium Conference Record, 3, 1567-1570.

[18] Germano, G., Chua, T., Kavanagh, P.B., Kiat, H. and Berman, D.S. (1993) Detection and Correction of Patient Motion 
in Dynamic and Static Myocardial SPECT Using a Multi-Detector Camera. Journal of Nuclear Medicine, 34, 13491355.

[19] Baggish, A.L. and Boucher, C.A. (2008) Radiopharmaceutical Agents for Myocardial Perfusion Imaging. Circulation, 118, 1668-1674. http://dx.doi.org/10.1161/CIRCULATIONAHA.108.778860

[20] Livieratos, L., Rajappan, K., Stegger, L., Schafers, K., Biley, D.L. and Camici, P.G. (2006) Respiratory Gating of Cardiac PET Data in List Mode Acquisition. European Journal of Nuclear Medicine and Molecular Imaging, 33, $584-588$. http://dx.doi.org/10.1007/s00259-005-0031-0

[21] Wang, Y., Riederer, S. and Ehman, R. (1995) Respiratory Motion of the Heart: Kinematics and the Implications for the Spatial Resolution in Respiratory Coronary Imaging. Magnetic Resonance in Medicine, 33, 713-719. http://dx.doi.org/10.1002/mrm.1910330517

[22] Wells, R.G., Ruddy, T.D., DeKemp, R.A., DaSilva, J.N. and Beanlands, R.S. (2010) Single-Phase CT Aligned to Gated PET for Respiratory Motion Correction in Cardiac PET/CT. Journal of Nuclear Medicine, 51, 1182-1190. http://dx.doi.org/10.2967/jnumed.109.070011

[23] Cooper, J., Neuman, P. and McCandless, B. (1992) Effect of Patient Motion on Tomographic Myocardial Perfusion Imaging. Journal of Nuclear Medicine, 33, 1566-1571.

[24] Rahmim, A. (2005) Advanced Motion Correction Methods in PET. Iranian Journal of Nuclear Medicine, 13, 1-17.

[25] Schafers, K. and Stegger, L. (2008) Combined Imaging of Molecular Function and Morphology with PET/CT and SPECT/CT: Image Fusion and Motion Correction. Basic Research in Cardiology, 103, 191-199. http://dx.doi.org/10.1007/s00395-008-0717-0

[26] Massardo, T., Jaimovich, R., Faure, R., Munoz, M., Alay, R. and Gatica, H. (2010) Motion Correction and Myocardial Perfusion SPECT Using Manufacturer Provided Software. Does İt Affect İmage İnterpretation? European Journal of Nuclear Medicine and Molecular Imaging, 37, 758-764. http://dx.doi.org/10.1007/s00259-009-1290-y

[27] Geckle, W.J., Frank, T.L., Links, J.M. and Becker, L.C. (1988) Correction for Patient and Organ Movement in SPECT: Application to Exercise Thallium-201 Cardiac Imaging. Journal of Nuclear Medicine, 29, 441-450. 